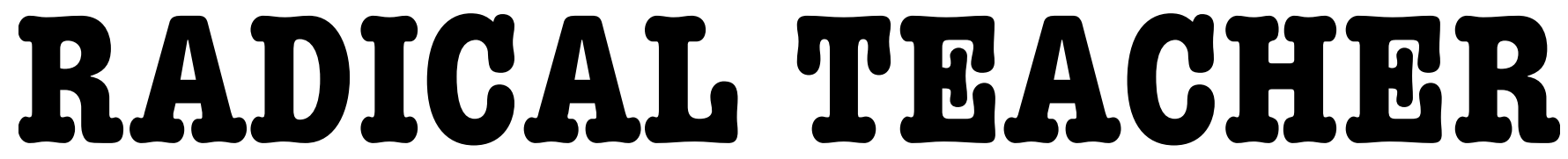

A SOCIALIST, FEMINIST, AND ANTI-RACIST JOURNAL ON THE THEORY AND PRACTICE OF TEACHING

\title{
Introduction: Archives and Radical Education
}

by Linda Dittmar and Joseph Entin

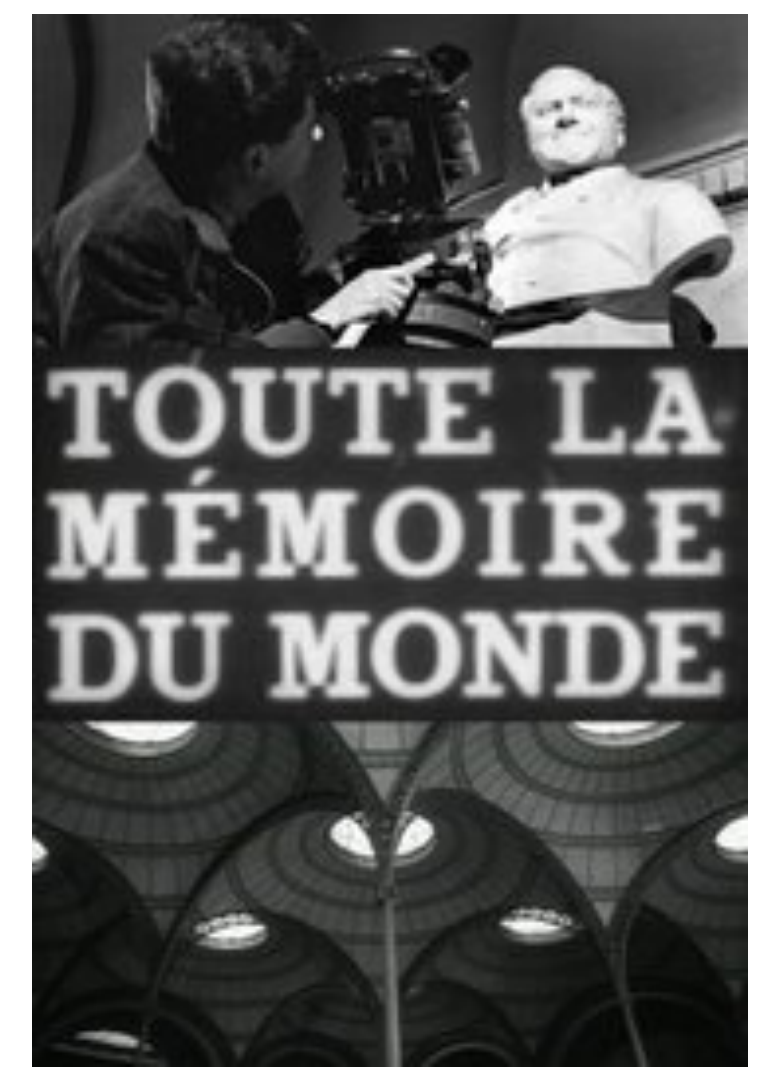

ALAIN RESNAIS' DOCUMENTARY FILM ABOUT THE FRENCH NATIONAL LIBRARY, ALL THE WORLD'S MEMORY (TOUTE LA MEMOIR DU MONDE) 
$\mathrm{T}$ hough Alain Resnais' documentary film about the French National Library, All the World's Memory (Toute la Memoir du Monde), is meant to celebrate the library's scope and organization, anxiety seeps into its cinematic "language": dim black-and-white footage, a restlessly prowling camera, close-ups that cut off object from context and detail from whole, discontinuous cuts, choppy bullet-like comments, and darkly foreboding orchestral music. It's a beautiful film, but what does it say about Resnais' feelings about the library? Certainly awe, but also high modernism's anxiety about proliferating knowledge. "Man," the authoritative male voice-over proclaims, "fears being engulfed by this mass of words."

In Jorge Luis Borges' "Library of Babel"-a surreal fiction rather than documentary-anxiety gives way to despair, where the profusion of knowledge overwhelms those who search for it. For all its discomfort, Resnais' film has confidence in order (and the labor that goes into it) as key to retrieval, while in Borges' library even its highly regulated architecture bewilders those who traverse it. Its books are stored in an "indefinite, perhaps infinite number of hexagonal galleries," each connected to its immediate neighbors in a mazelike array of unknown options. As more and more seekers set out to find the "books of Vindication" that will justify all actions for all times, as they believe, a mad stampede for the texts that offer that salvation ensues.

A $20^{\text {th }}$-century anxiety about the quantity and use of available knowledge haunts these accounts. Resnais'

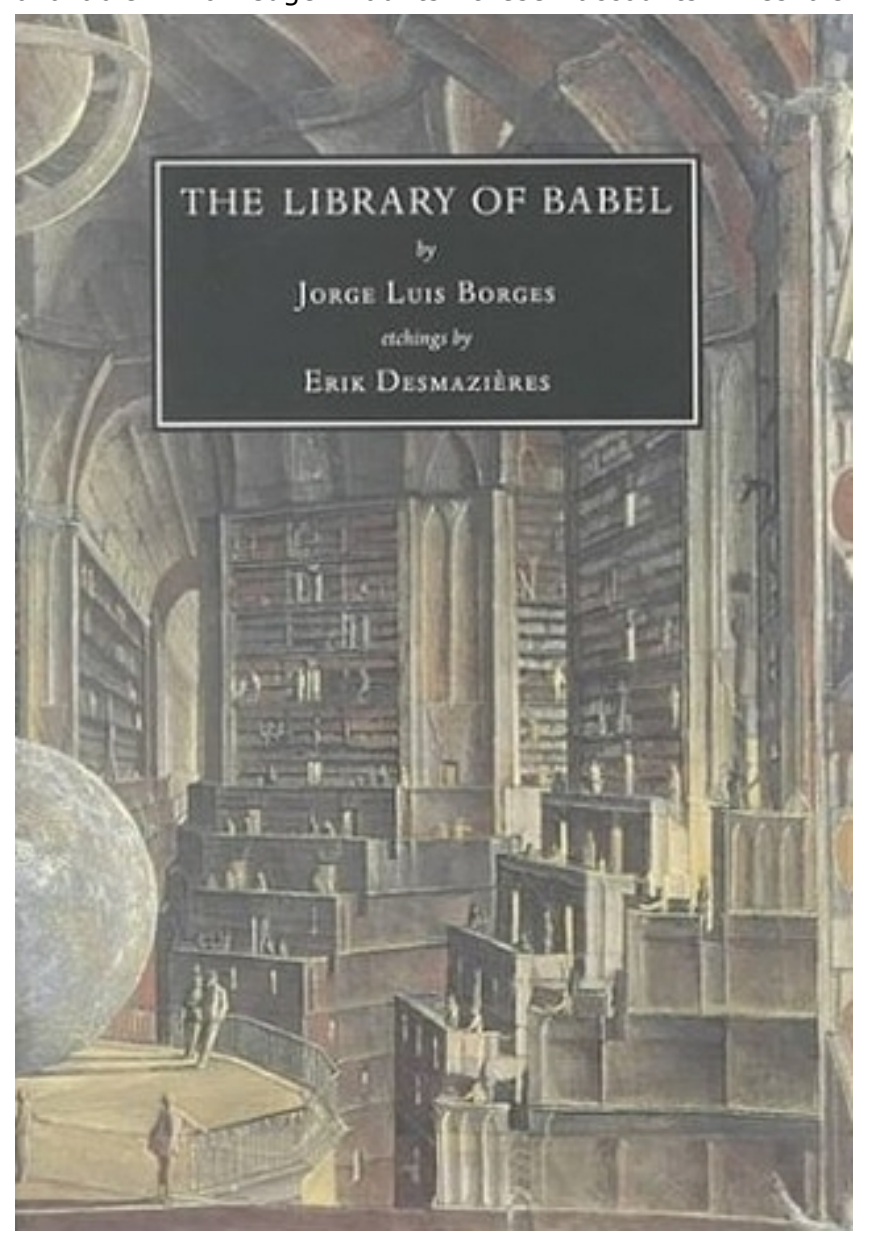

library is being dug ever deeper into the ground and built ever higher toward the sky to accommodate the multiplying "mass of words" that is "engulfing" it. Borges' hexagonal containers extend beyond anyone's ability to chart; like its namesake, the tower of Babel, the library's seemingly rational arrangement becomes the site of chaos.

In a sense, these dark accounts are not so much about libraries as they are about the human brain, with its "hexagons" and neurons working hard to navigate everything from putting one foot in front of another to responding to a world crisis. For libraries and archives, though, the situation is changing now that we are entering a digital age, albeit in ways that we cannot yet predict. While available knowledge is multiplying many times over, so are systems of storage and retrieval. Wikipedia, Google, YouTube, and Wikileaks are well known but hardly the only examples of this turn-around. The capacity to digitize and disseminate has grown exponentially, creating different staffing and budget challenges but also raising questions of ownership and access, participation and exclusion, reliability, oversight and censorship.

\section{Many other archives could have been included in this cluster, from archived African American history to the New England Textile Museum or Argentina's Mothers of Plaza del Mayo. These and many others register the need to preserve and store other documents relevant to progressives.}

These are old questions, though they may require new responses from researchers and educators, including radicals. While this means that there are struggles ahead, the articles submitted to this special issue of Radical Teacher reflect optimism regarding a radical practice of teaching with archives. There's the verve of discovery here, of energy about re-appropriating conventional archives, accessing marginal knowledge, and expanding the definition of "archive." In her contribution, Ellen Schrecker reminds us of the usefulness of mainstream archives (e.g. FBI files and the Hoover Institute) for radical research. Her sobering caution concerns funding - a cause for concern for small alternative archives and radical ones in particular. Other contributors also discuss archives that consist of paper and other tangible objects, though their holdings are of more direct use to radicals: the Peace Archive at Haverford College, Asian-American zines, Interference Archive's social movement collection, the Lesbian Herstory Archive in Brooklyn, oral histories of the India/Pakistan Partition, and iLand's collection of performative movement "scores."

Many other archives could have been included in this cluster, from archived African American history to the New England Textile Museum or Argentina's Mothers of Plaza del Mayo. These and many others register the need to preserve and store other documents relevant to progressives. As teachers and archive users, contributors 
to the present cluster of articles highlight that certain texts need to be preserved as tools of knowledge, debate, and contestation. They emphasize a critical, self-aware use of archives and redefine "archives" to broaden the rationale for their particular assembly so as to include unstable materials such as oral histories and transitory, time-based performances that are by definition ephemeral. ${ }^{1}$

These departures from conventional archives raise the question of what is an "archive" in the first place. This definitional question has been the subject of much discussion in recent decades, as scholars across several academic and intellectual fields have initiated an "archival turn"-a growing interest in the concept of the archive and a rethinking of traditional notions of what archives are, what they hold, and how they are constructed, maintained, and used. Several things have sprung from this newly intensified focus on archives, starting with a questioning and expansion of the meaning of the term itself. If a standard dictionary definition refers to an archive as "a place where documents and other materials of public or historical interest are preserved," today the term is often used not merely to describe traditional institutional repositories in museums and libraries, but a wide array of sitessome material, some virtual, some institutional, some defiantly antiinstitutional-that house a striking range of materials, not just traditional documents, but items of popular culture, social movement ephemera, material objects, and much more. ${ }^{2}$ Librarian Melanie Manoff argues that in the contemporary digital era, the term archive itself is "loosening and exploding," becoming "a kind of loose signifier for a disparate set of concepts. ${ }^{\prime 3}$

In a second, related development, long-standing notions of archives as neutral repositories of historical fact are being called into question. Drawing in particular on Michel Foucault's conception of powerknowledge and Derrida's Archive Fever, which argues, among other things, that "there is no political power without control of the archive," historians, anthropologists, activists, and archivists themselves have placed new emphasis on the role archives play in contests over social, historical, and cultural authority. ${ }^{4}$ Archives consolidate objects as sources of knowledge, and in so doing, they help construct boundaries around what counts as history and whose stories are likely to be told. Archives do not simply provide direct access to historical information; rather, they shape and organize what counts as history, and how history is framed and understood.

As the etymology of the term itself implies, archives are often the province of the powerful, who have the resources to preserve and regulate access to materials in ways that narrate the world from the perspective of history's winners. ${ }^{5}$ Archives can also play an active role in producing social hierarchies. Photographer, filmmaker, and critic Allan Sekula has argued, for instance, that latenineteenth-century photography was integrated into "a generalized, inclusive archive, a shadow archive," designed to define and regulate social deviance. ${ }^{6}$ Criminologists, anthropologists, and other social scientists and bureaucrats, Sekula explains, developed a massive archive of photographic images for the purposes of identifying criminals and other putatively subversive figures by physiological type. Ann Laura Stoler has argued that archives were crucial to European colonialism, not only as repositories that contain a record of colonial power relations, but also as "intricate technologies of rule in themselves." ${ }^{\prime 7}$ Colonial authorities collected and preserved records and data that not only documented, but also justified and legitimated their colonial regimes.

Yet however much archives are shaped to naturalize the rule of history's winners, such archives can of course be read against the grain. Stoler argues for an "ethnographic" approach to archives, in which scholars move from treating archives as transparent repositories of historical evidence, to subjects that themselves need to be critically interrogated. Stoler asserts that colonial archives need to be read against the grain, for their silences and gaps, and along the grain as well, to understand and decipher their prevailing logics, modes of order, and relations to dominant institutions. Recently, Lisa Lowe has proposed a mode of reading archives "intimately," often in defiance of accepted national boundaries and chronologies, to trace the typically occluded links between Western liberalism, settler colonialism, and slavery. ${ }^{8}$ As activists and radicals have shown over the years (see the Pentagon Papers and Wikileaks), the archives of the powerful can be redeployed to challenge the very sources of power they are often designed to protect and legitimate. $^{9}$

Archives are always built on exclusions and omissions, as the boundaries drawn around them preserve some materials at the expense of others. The creation of counter-archives designed to legitimize histories and communities that have been neglected or suppressed by official record-keeping has proved to be a potent form of activist scholarship. The growth of this alternative archival infrastructure dates back at least to the early $20^{\text {th }}$ century, and the founding of early archives of African American history and culture, including the New York Public Library's Schomburg Center for Research in Black Culture, the Moorland-Springarn Research Center at Howard University, and the Amistad Research Center at Tulane University. A much more recent example, outside the auspices of a major library or university, is the Weeksville Heritage Center in Brooklyn, NY-"a multidisciplinary museum dedicated to preserving the history of the 19th century African American community of Weeksville, Brooklyn - one of America's first free black communities. . . . Weeksville 
advances its mission through history, preservation, visual and performing arts, ecology and the built environment."10

\section{These departures from conventional archives raise the question of what is an "archive" in the first place.}

Modern and contemporary artists have also been mining the archive's radical use, especially given the truthclaims of photography, film, and tangible objects. One example is the path-breaking exhibition, "Archive Fever: Uses of the Document in Contemporary Art." As NigerianAmerican critic, poet, curator and educator Okwui Enwezor writes in his curatorial essay about this exhibition (whose title, not incidentally invokes Derrida's book by the same title), archives are anything but "inert repositories of historical artifacts." Rather, the contemporary artists whose work he includes in this exhibition "have appropriated, interpreted, reconfigured, and interrogated archival structures and archival materials . . . as an archival record, as an analogue of a substantiated real or putative fact. ${ }^{\prime 11}$

From James Allen's collection of souvenir postcards of lynching, Without Sanctuary, to Andy Warhol pillaging public records of race riots or the photos of Abu Ghraib, the power of these compendia exceeds their subject matter with its stubbornly cumulative repetition. In American artist Fazal Sheikh's "The Victor Weeps: Afghanistan" a series of hands hold tiny passport images of dead family members. Colombian artist Doris Salcedo's Atrabiliarios has shoes of the disappeared, mostly women, stored in shoebox-like niches sunk into the wall, each ghostlike behind a thin animal skin sutured over the nooks. Engaging viewers in active investigation, artist Walid Raad ascribes his imageseries about the history of contemporary Lebanon to the non-existent Atlas Group's ostensible "archive." In one photo series that shows journalists looking at car engines destroyed in car bombings, the multiplied banality of the rendition as well as opacity of the political events strand viewers between horror at the event and distance from how it's shown.

As the above suggests, specialized archives often aim to set straight a historical record. Some do so by actively contesting official knowledge, shifting the burden to us, the users. Some do so in celebration of retrieved content, some in protest against its suppression, often both. Holocaust archives, for example, meld mourning and commemoration with the implicit warning of "never again." Maya Lin's Vietnam Memorial and the AIDS quilt similarly mourn and commemorate, but also agitate and invite reflection about the broader implications of the traumas they register. Archives of the Nakba (Palestinian "catastrophe"/expulsion in 1948) and Palestinian resistance, especially martyrdom, similarly commemorate trauma, except that their engagement in current political struggles renders them militant. ${ }^{12}$ The \#FergusonSyllabus twitter campaign, started by Georgetown history professor Marcia Chatelain in response to the killing of unarmed 18year-old African American Michael Brown by Ferguson,
Missouri police officer Darren Wilson in 2014, allowed educators to build collaboratively a virtual, social media archive of sources for teaching against racial injustice.

This issue of Radical Teacher addresses the way that progressive educators engage archives. How do radical teachers use archives in (or outside) their classrooms and with their students? J. Ashley Foster, Sarah Horowitz, and Laurie Allen describe teaching with a capacious "peace archive," containing both pacifist works of art by radical early twentieth-century modernist writers and painters, and the Quaker peace collection at Haverford College. Ultimately, students added their own contributions to the record, building an exhibition on pacificism in the face of total war that included their own peace manifestoes. Kailah Carden and Sabrina Vaught, writing with students Arturo Muñoz, Vanessa Pinto, Cecelia Vaught and Maya Ziegler, describe teaching a course on radical lesbian thought with and through the Lesbian Herstory Archives. In their class, as well, students not only used the archive as a source of knowledge, but also as an inspiration for their own archival projects, which collectively challenged the possibility that any archive can offer a complete or authoritative record.

Also describing the way students move from researchers to knowledge producers, Todd Honma's article describes an Asian-American studies class in which students delve into the 1970s zine Girda, digitally available at the on-line Densho Archive, before creating zines of their own that address gentrification in Los Angeles's contemporary Chinatown community. Gaana Jayagopalan's use of oral histories to study the partition of India and Pakistan has special immediacy in her classroom, as this event is still an open wound for many in India (and across its border to Pakistan), Hindu and Muslim alike. These oral histories contest the hegemony of the knowledge proffered by official accounts, enabling her students to grasp dimensions of personal trauma and grief that are largely effaced by the State's emphasis on grand geopolitical narratives. Bonnie Gordon, Lani Hanna, Jen Hoyer and Vero Ordaz describe the ethos of open access at the heart of Interference Archive, a participatory social movement repository in Brooklyn, New York. Run entirely by volunteer labor, Interference Archive allows teachers, students, and the wider public to help shape the way history itself is preserved and presented. Ann Holt and Chris Kennedy also stress the responsive, evolving quality of archives in their piece on iLAND's repository of movement "scores," or scripts, which are designed to be actively re-used and revised by the archive's users.

\section{Specialized archives often aim to set straight a historical record. Some do so by actively contesting official knowledge, shifting the burden to us, the users.}

As these essays suggest, the use of archives is participatory, open to the intention of its users. This is especially evident when their use involves self-aware radical teaching, where archives' availability to their users' 
selection and configuration becomes, itself, subject to analysis. A question that arose for us, the editors of this cluster, is what in fact is "radical" about using archives beyond the fact that bringing a given subject matter to light intervenes in, and attempts to trouble or transform, conventional knowledge. For instance, is teaching about the India/Pakistan Partition through oral histories and with emphasis on its affective dimensions in itself radical? Are the essentially impermanent collaborations in the iLAND archive radical because they challenge our sense of fixed modes of selecting and knowing our world? While such questions may emerge more explicitly in some of our essays, they are in fact ones to consider in relation to this cluster as a whole. Keeping these questions in mind, we hope this issue provides a useful, thought-provoking, and perhaps even inspiring look at the creative work that radical teachers and their students are doing to use, create, and question archives across a range of educational contexts.

\section{Notes}

1 In their use of heterogeneous materials and many speakers, radical compilation documentaries such as those produced in the 1960s and 70 s can also be considered mini archives. These include films about American labor, the Civil Rights and Black Power movements, The Vietnam war, the Red Scare in Hollywood, the American anarchists, and the Lincoln Brigade. Such film, like a book that collects oral histories, is archival in its sources and in exposing their plurality, except that it's pre-selected and sequenced organization precludes the rummaging and discovery that are the hallmark of archival research.

2 Dictionary definition cited in Melanie Manoff, "Theories of the Archive from Across the Disciplines," portal: Libraries and the Academy, Vol. 4, No. 1 (2004), 10.

3 Ibid.

4 Jacques Derrida, Archive Fever: A Freudian Impression, trans. Eric Prenowitz (Chicago: University of Chicago Press, 1995), 4.

5 The Latin word archivum, "resident of the magistrate," and the Greek term arkhe, to command or govern, both suggest links between record-keeping and political authority or rule. And, as archivists Joan Schwartz and Terry Cook observe, the origin of archives "lie in the information needs and social values of the rulers, governments, businesses, associations, and individuals who establish and maintain them." Joan M. Schwartz and Terry Cook, "Archives, Records, and Power: The Making of Modern Memory," Archival Science 2 (2002), 3.

6 Allan Sekula, "The Body and the Archive," October, Vol. 39 (Winter 1986), 10.

7 Ann Laura Stoler, "Colonial Archives and the Arts of Governance," Archival Science, Vol. 2 (2002), 87.

8 Lisa Lowe, The Intimacies of Four Continents (Durham, NC: Duke University Press, 2015).

9 "Archives have the power to privilege and to marginalize," argue archivists Joan Schwartz and Terry Cook. "They can be a tool of hegemony; they can be a tool of resistance. They both reflect and constitute power relations." Schwartz and Cook, "Archives, Records, and Power," 13.

10 http://www.weeksvillesociety.org/what-we-do/.

11 Okwui Enwezor's essay, "Archive Fever: Photography between History and the Monument," is available in PDF at sites.duke.edu.The ICP exhibition he curated, "Archive Fever: Uses of the Document in Contemporary Art," showed at the International Center for Photography, New York, 2007.

12 See Miki Kratsman and Ariela Azoulay, The Resolution of the Suspect (Cambridge, Peabody Museum and Santa Fe, Radial Books). Kratsman's photographic work includes portraits of Palestinians taken with a military camera that sets them up as "targets," neighborhood posters of shahids (martyrs), and photo-journalistic images of living people framed as "wanted" because they were eventually killed.
RADICAL TEACHER 


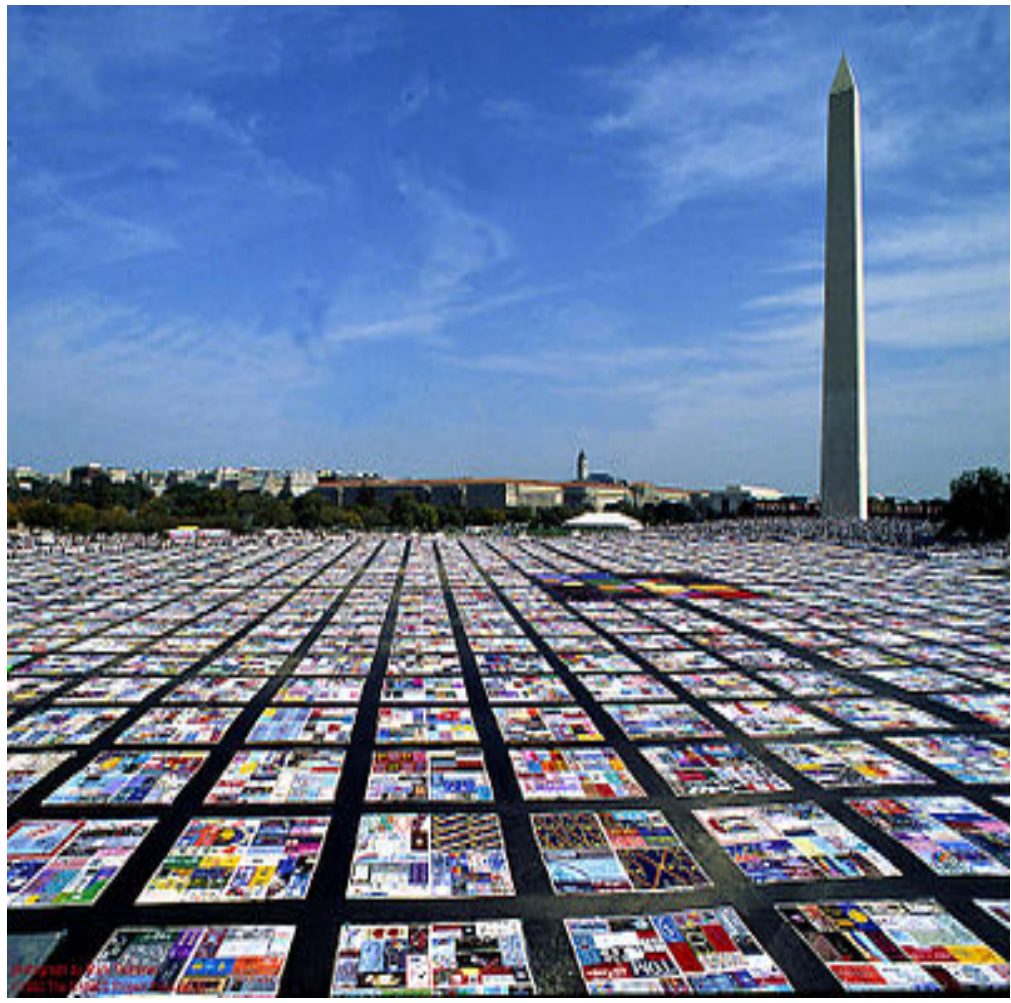

A DIFFERENT SORT OF ARCHIVE THE NAMES PROJECT AIDS QUILT

\section{$(\mathrm{oc}) \mathrm{EY}-\mathrm{NC}-\mathrm{ND}$}

UILIS D-Sork
This work is licensed under a Creative Commons Attribution-Noncommercial-No Derivative Works 3.0 United States License.

This journal is published by the University Library System of the University of Pittsburgh as part of its D-Scribe Digital Publishing Program, and is cosponsored by the University of Pittsburgh Press.

\section{RADICAL TEACHER}

http://radicalteacher.library.pitt.edu 